\title{
Scar adenocarcinoma of the lung: a light and electron microscopic study
}

\author{
C EDWARDS, A CARLILE
}

From the Department of Histopathology, East Birmingham Hospital, Birmingham

SUMMARY Five well differentiated peripheral adenocarcinomas of the lung were investigated, using light and electron microscopy. Each tumour contained a central nidus of fibrous tissue and fulfilled the criteria for "scar cancer." One tumour also had a focus of lamellated collagenous tissue, suggestive of an old tuberculous granuloma. Electron microscopy showed the features of Clara cells, with characteristic dense bodies in the apical cytoplasm and scattered microvilli on the luminal surface.

It was concluded that this variant of scar cancer was a carcinoma of Clara cells, which was sufficiently distinctive in appearance to be recognised on light microscopy alone. It remains uncertain, however, whether the central fibrous area is a desmoplastic response to tumour growth or a pre-existing scar.

Peripheral carcinomas of the lung often contain a central zone of connective tissue: they may arise as the result of malignant transformation of epithelium adjacent to a pre-existing $\operatorname{scar}^{1-4}$ although this hypothesis has been questioned in recent years. ${ }^{5-7}$ Most such "scar cancers" are adenocarcinomas but some are squamous or large cell undifferentiated tumours. ${ }^{48}$

Ultrastructural studies have shown that peripheral adenocarcinoma-in common with alveolar carcinoma-may consist of mucus cells, type II cells, or Clara cells, or a combination of all three. ${ }^{9-14}$ The main purpose of our investigations, however, was to define the cellular subtypes of adenocarcinoma in general, and little attention was paid to scar cancer as such.

In this paper we describe the ultrastructure of five well differentiated peripheral adenocarcinomas that were associated with a focus of scarring.

\section{Material and methods}

Material was obtained from two men and three women aged between 51 and 71 years, undergoing lobectomy for peripheral adenocarcinoma. The tumours were between 1.5 and $4 \mathrm{~cm}$ in diameter, none of which was located around a major bronchus: three were in the left lower lobe, one in the left upper lobe, and one in the right upper lobe. Four showed the characteristic puckering of the overlying visceral

Accepted for publication 11 December 1985 pleura. The tumour in the right upper lobe had extended across the pleural space into intercostal tissue, necessitating rib resection in addition to lobectomy. There was no evidence of fibrosing alveolitis in any of the cases.

Specimens for electron microscopy were taken at the time of operation, fixed in buffered glutaraldehyde, then fixed in osmic acid and embedded in TAAB resin. Ultrathin sections were stained with uranyl acetate and lead citrate. Sections for light microscopy were stained with haematoxylin and eosin, periodic acid Schiff with and without diastase (PAS and PASD), alcian blue at pH 2.1, and Miller's elastic van Gieson stain.

\section{Results}

\section{LIGHT MICROSCOPY}

Each tumour had three distinct zones (Figs. 1-4). The central area consisted of eosinophilic elastic and collagen fibres, fibroblasts, a few chronic inflammatory cells, and capillaries. Staining with elastic van Gieson showed the outlines of partially collapsed alveoli and obliterated vessels (Fig. 2). Alveolar lumens were filled with fine collagen fibres. In one case there was also a central aggregate of coarse partly necrotic collagen fibres, arranged in concentric layers, sharply demarcated from adjacent fibrous and elastic tissue.

More peripherally, the fibrous tissue was infiltrated by round or irregular neoplastic acini, containing cell debris of amorphous eosinophilic material (Fig. 3). This pattern of a well differentiated desmoplastic ade- 
Fig. 1 Scar adenocarcinoma. Central part of tumour consists of a mass of elastic and collagen fibres. At the periphery pattern is that of an alveolar carcinoma, sharply demarcated from adjacent lung parenchyma (arrows). Higher power view of the edge of tumour is shown in Fig. 4 (Elastic van Gieson.) $\times 5$.

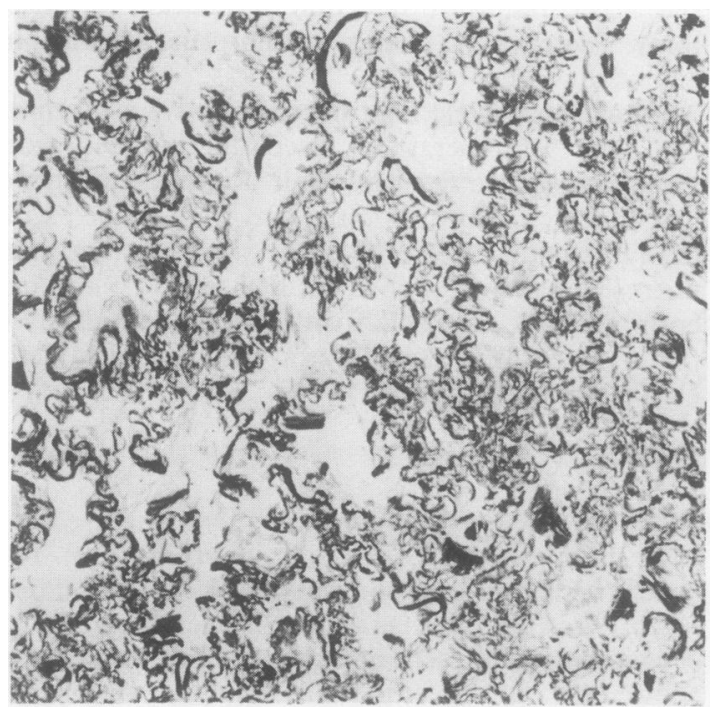

Fig. 2 Central scar consists of elastic outlines of partly collapsed alveoli containing five collagen fibrils. (Elastic van Gieson.) $\times 94$.

nocarcinoma then gradually changed to that of an alveolar carcinoma with thickened septa lined by tumour cells (Fig. 4). At the extreme edge there was an abrupt transition from abnormally wide alveolar septa to septa of normal thickness.

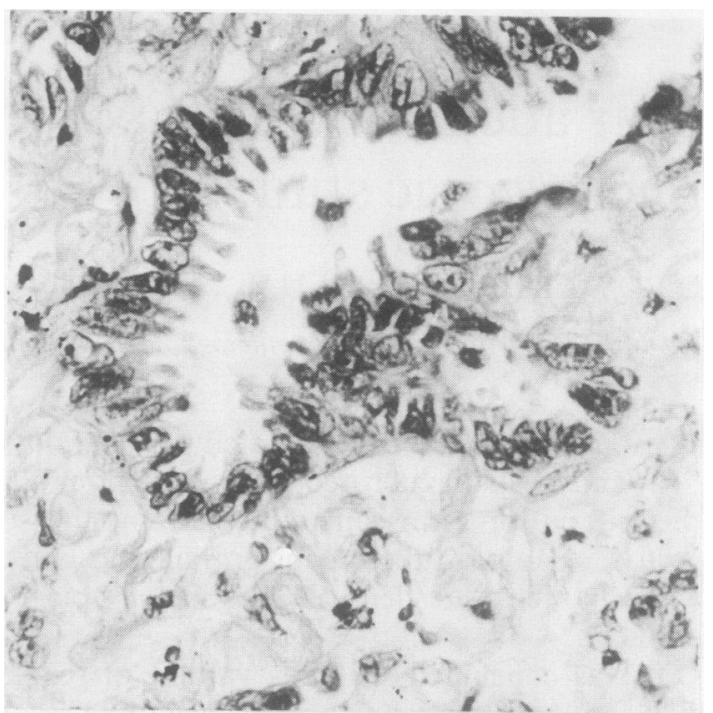

Fig. 3 Scar tissue infiltrated by well differentiated adenocarcinoma. There are tongue like protrusions at cell apices. (Haematoxylin and eosin.) $\times 263$.

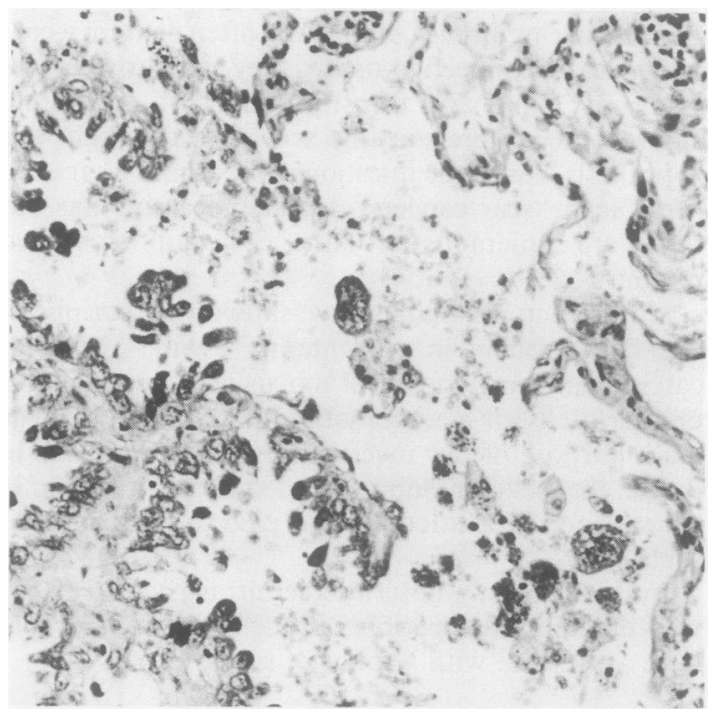

Fig. 4 Edge of tumour, showing pattern of an alveolar carcinoma with thickened alveolar septa on the left and normal alveolar septa on the right. (Haematoxylin and eosin.) $\times 210$.

Acini and alveoli were lined by cuboidal or columnar cells up to $45 \mu \mathrm{m}$ in height, sometimes with a tongue like protrusion at the apex (Fig. 3). Nuclei were round or irregular, usually basal and up to $15 \mu \mathrm{m}$ in maximum diameter. The chromatin pattern was diffuse or open, and sometimes there was a prominent eosinophilic nucleolus. There were moderate 


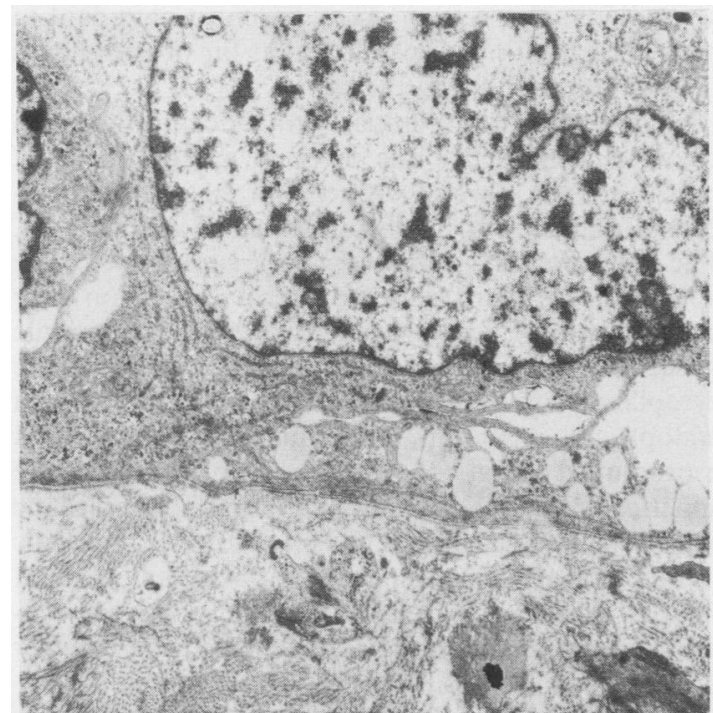

Fig. 5 Basal portions of two tumour cells, resting on thin basement membrane, beneath which is layer of condensed collagen fibrils. Vacuoles containing faintly staining amorphous material lie just inside cytoplasmic membrane. $\times$ 7100 .

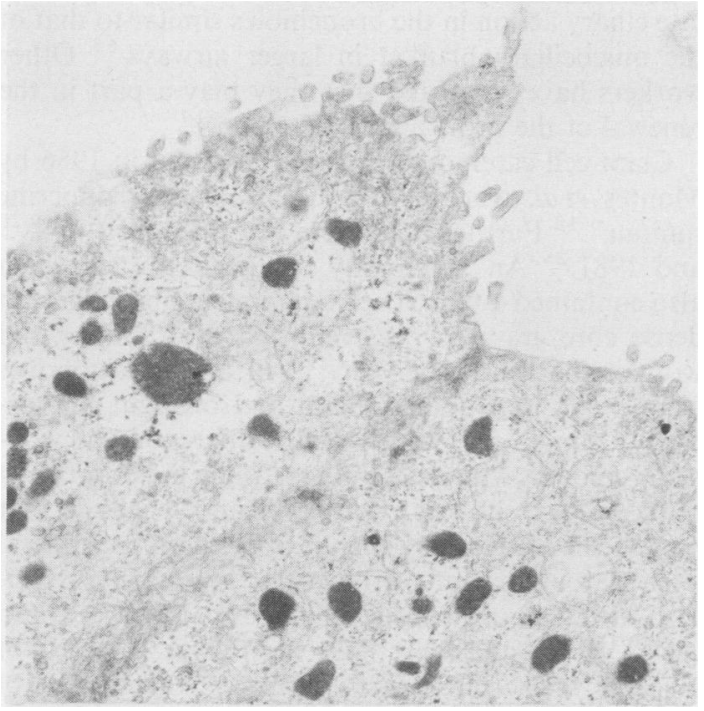

Fig. 6 Apices of two tumour cells with surface microvilli and intracytoplasmic inclusion bodies. $\times 9200$.

numbers of mitoses. The cytoplasm was generally slightly granular and eosinophilic, but very occasionally there were ill defined vacuoles containing PAS positive diastase resistant material, which also stained with alcian blue. Although the cytoplasm of most cells was negative for both these stains, there was always a prominent layer of positive material on

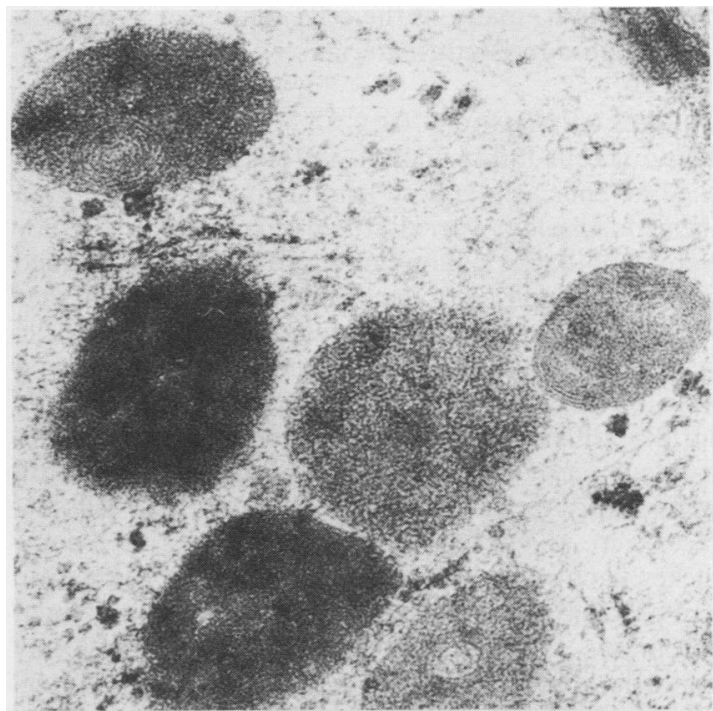

Fig. 7 Granular intracytoplasmic inclusions, some of which show finger print pattern. $\times 56700$.

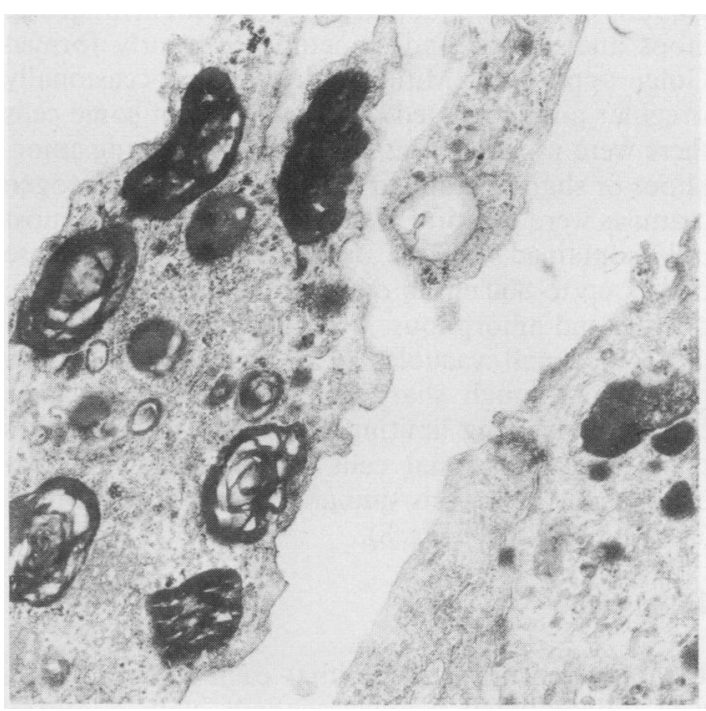

Fig. 8 Intracytoplasmic lamellar inclusions in tongue like process extending into lumen. Amorphous and granular bodies are present in cell on the right. $\times 21000$.

the luminal surface, and occasionally the contents of acini were also positive.

In all the specimens the tumour had spread to the overlying visceral pleura, and in one case had extended into intercostal tissue. Hilar nodes were affected in two instances. The secondary tumour consisted of poorly differentiated large cells with only minimal acinar differentiation. In contrast to the pri- 
mary tumour, many of the cells contained PAS positive diastase resistant material.

\section{ELECTRON MICROSCOPY}

Tumour cells lining acini in fibrous tissue and thickened alveolar septa were similar in appearance, and their morphology varied little from case to case. They were cuboidal or columnar, resting on a well defined layer of condensed collagen fibrils from which they were separated by a thin membrane (Fig. 5). Nuclei were round or oval with a prominent nucleolus and were often deeply indented (Fig. 5). On the luminal surface there were usually irregular, sometimes stunted microvilli, but in some instances the microvilli were scanty or absent (Fig. 6). Juxtaposing cell surfaces were joined near the lumen by junctional complexes, each consisting of a well defined tight junction, gap junction, and desmosome. Deep to the junctional complexes adjacent cell membranes were closely applied, or separated by a gap bridged by interdigitating cytoplasmic process.

Some cells were rather featureless with scanty organelles, but, in general, there was a moderate amount of rough endoplasmic reticulum arranged in loops and whorls and sometimes a poorly formed Golgi apparatus. Mitochondria were occasionally irregular and elongated. In basal parts of some cells there were vacuoles containing faintly staining amorphous or slightly granular material (Fig. 5). Glycogen granules were plentiful. The apical cytoplasm of most cells contained variable numbers of electron dense bodies up to $800 \mathrm{~nm}$ in diameter (Fig. 6). Some were opaque and amorphous, whereas others were granular, with small vacuoles or a finger print pattern (Fig. 7). Although sharply demarcated, rarely was there a convincing limiting membrane. In two cases there were occasional cells with lamellated intracytoplasmic inclusions similar to the surfactant bodies of type II cells (Fig. 8).

\section{Discussion}

Light microscopy showed that each tumour was a well differentiated adenocarcinoma, with a central nidus of connective tissue and an alveolar pattern of spread at the periphery. Each fulfilled the criteria for scar cancer as originally proposed by Friedrich ${ }^{1}$ namely, no relation to a major bronchus, contiguity with a hyalinised scar, and absence of tumour cells in the scar itself. In all five cases the ultrastuctural morphology was that of a Clara cell neoplasm.

Clara cells - or non ciliated bronchiolar secretory cells-were first described by Kölliker in $1881^{15}$ and later studied in detail by Max Clara ${ }^{16}$ after whom they are named. Since then their ultrastructure and histochemistry have been investigated in man and in several animal species. ${ }^{15}$ They are most abundant in bronchioles but have been found as far proximally as the pulmonary hilus in the rat. ${ }^{15}$

Clara cells ${ }^{15}$ are columnar, protrude into the bronchiolar lumen above the level of adjacent ciliated cells, and rest on the bronchiolar basement membrane. The nucleus is centrally situated and cleaved. The apex is often in the form of a cap or bleb. The apical surface bears scattered microvilli, and on their lateral borders there are interdigitating cytoplasmic processes with tight junctions and desmosomes. The cytoplasm contains abundant smooth and rough endoplasmic reticulum, numerous mitochondria, and a prominent Golgi zone. In the apical cap there are spherical mitochondria, profuse smooth endoplasmic reticulum, and sometimes myelin figures. Osmiophilic intracytoplasmic inclusion bodies between 300 and $700 \mathrm{~nm}$ in diameter are characteristic. They are usually amorphous or granular, but may have a finger print or lamellated pattern.

The function of Clara cells remains uncertain. Enzyme histochemistry has shown that they are metabolically highly active. It has been proposed that they contribute to the surfactant layer in bronchioles and to the hypophase layer in alveoli. It has also been suggested that they secrete a watery medium to facilitate ciliary action in the bronchioles similar to that of the mucociliary blanket in larger airways. ${ }^{15}$ Other workers have suggested that they play a part in the renewal of the bronchilar epithelium. ${ }^{17}$

Clara cell carcinoma was first reported in 1966 by Montes et al, who named it "bronchiolar apocrine tumour". ${ }^{18}$ Further cases were described in $1977^{1920}$ and $1981 .{ }^{21}$ An apparently benign example, which also contained a type II cell component and cells with dense core granules, was reported in a 25 year old woman the following year. ${ }^{22}$ All of these tumours were subpleural or peripheral and on light microscopy four ${ }^{18-21}$ were well differentiated adenocarcinomas with a central scar and lepidic spread at the edge. One showed extensive clear cell change. ${ }^{20}$ It now seems likely that a high proportion of peripheral adenocarcinomas of the lung, not necessarily associated with scarring, consist wholly or partially of Clara cells, ${ }^{9121323}$ and there have been several reports of alveolar cell carcinoma showing this type of differentiation. ${ }^{1424}$ Clara cell carcinomas may have a better prognosis than mucus cell carcinomas or mixed adenocarcinomas with a mucus cell component. ${ }^{1218-20}$

The role of scarring in the pathogenesis of lung cancer is controversial. It was originally postulated that a proportion of such tumours arise at the edge of pre-existing scars. In older reports most of these scars were considered to be tuberculous, ${ }^{1-3}$ but subsequently infarcts, foreign bodies such as knife blades 
and grenade splinters, and other causes of localised scarring including Hodgkin's disease have been implicated. ${ }^{45}$ The hypothesis has been extended to include tumours developing in association with diffuse lung disease, ${ }^{25}$ and several workers have described epithelial proliferation and atypia in damaged lung tissue. $^{26-29}$ It has been suggested that a lymphatic obstruction results in a high local concentration of carcinogens, which in turn causes malignant transformation. ${ }^{26}$ Others are of the opinion that the scarring represents a desmoplastic reaction and is the result, rather than the cause, of tumour growth. ${ }^{56}$ Recently, Madri and Carter ${ }^{7}$ showed that there was a high concentration of type III collagen in scar cancers, which would indicate that the fibrous tissue is in an active "immature" state. In contrast, nonneoplastic fibrous tissue is mature and contains mainly types I and $\mathrm{V}$ collagen.

No definite conclusions can be drawn, and, notably, one of the main protagonists of the "desmoplastic" school was unable to refute entirely the scar cancer hypothesis. ${ }^{6}$ The central focus of lamellated hyaline fibrous tissue in one of our cases was entirely consistent with old tuberculosis. In the others, however, the fibrotic area could be interpreted as either a pre-existing scar or a scirrhous reaction, and the thickening of the alveolar walls at the periphery of the lesion suggests that the neoplastic cells had elicited a fibrogenic response.

Whatever the nature of the central scar, the results of our study indicate that this variant of "scar cancer" is a tumour of Clara cells, and its appearance is sufficiently characteristic to permit diagnosis on light microscopy alone. Its prognosis, compared with that of other peripheral lung neoplasms, has yet to be clarified.

We thank Mrs Ruth Fry for secretarial help.

This work was supported by a grant from the West Midlands Health Authority.

\section{References}

${ }^{1}$ Friedrich G. Periphere Lungenkrebse auf dem Boden pleuranaher. Virchows Arch (Pathol Anat) 1939;304:230-47.

${ }^{2}$ Yokoo H, Suckow EE. Peripheral lung cancer arising in scars. Cancer 1961;14:1205-15.

${ }^{3}$ Carroll $R$. The influence of lung scars in primary lung cancer. $J$ Pathol Bacteriol 1962;83:293-7.

${ }^{4}$ Auerbach O, Garfinkel L, Parks VR. Scar cancer of the lung. Increase over a 21 year period. Cancer 1979;43:636-42.
${ }^{5}$ Gray RE, O'Neal RM. Multiple pulmonary scar carcinomas in a patient with Hodgkin's disease: report of a case and review of the literature. Cancer 1980;46:1868-72.

${ }^{6}$ Shimosato Y, Hashimoto T, Kodama T, et al. Prognostic implications of a fibrotic focus (scar) in small peripheral lung cancers. Am J Surg Pathol 1980;4:365-73.

${ }^{7}$ Madri JA, Carter D. Scar cancers of the lung: origin and significance. Hum Pathol 1984;15:625-31.

${ }^{8}$ Ochs RH, Katz AS, Edmunds LH, Miller CL, Epstein DM. Prognosis of pulmonary scar carcinoma. J Thorac Cardiovasc Surg 1982;84:359-66.

${ }^{9}$ Kimula Y. A histochemical and ultrastructural study of adenocarcinoma of the lung. Am J Surg Pathol 1978;2:253-64.

${ }^{10}$ Bolen JW, Thorning D. Histogenetic classification of pulmonary carcinoma. Peripheral adenocarcinomas studied by light microscopy, histochemistry and electron microscopy. Pathol Annu 1982;17:77-100.

${ }^{11}$ Sidhu GS. The ultrastructure of malignant epithelial neoplasms of the lung. Pathol Annu 1982;17:235-66.

${ }^{12}$ Herrera CA, Alexander B, de Moraes HP. Ultrastructural subtypes of pulmonary adenocarcinoma. A correlation with patient survival. Chest 1983;84:581-6.

${ }^{13}$ Rainio P. Ultrastructure of neoplastic cells in different histologic subtypes of pulmonary adenocarcinoma. Pathol Res Pract 1983;176:216-35.

${ }^{14}$ Alveolar carcinoma: a review. Thorax 1984;39:166-74.

${ }^{15}$ Breeze RG, Wheeldon EB. The cells of the pulmonary airways. Am Rev Respir Dis 1977;116:705-77.

${ }^{16}$ Clara M. Zur Histobiologie des Bronchialepithels. Zeitschrift für Mikroskopisch-Anatomische Forschung (Leipzig) 1937;41: 321-47.

${ }^{17}$ Evans MJ, Cabral-Anderson LJ, Freeman G. Role of the Clara cell in renewal of the broncholar epithelium. Lab Invest 1978;38:648-55.

${ }^{18}$ Montes M, Adler RH, Brennan JC. Bronchiolar apocrine tumour. Am Rev Resp Dis 1966;93:946-50.

${ }^{19}$ Montes M, Binette JP, Chaudhry AP, Adler RH, Guarino R. Clara cell adenocarcinoma. Am J Surg Pathol 1977;1:245-53.

${ }^{20}$ Sidhu GS, Forrester EM. Glycogen-rich Clara cell-type broncholoalveolar carcinoma. Cancer 1977;40:2209-15.

${ }^{21}$ Zolliker AS, Jacques J. Clara cell carcinoma of the lung. Hum Pathol 1981;12:748-50.

${ }^{22}$ Fantone JC, Geisinger KR, Appleman HD. Papillary adeoma of the lung with lamellar and electron dense granules. An ultrastructural study. Cancer 1982;50:2839-44.

${ }^{23}$ Ogata T, Endo K. Clara cell granules of peripheral lung cancers. Cancer 1984;54:1635-44.

${ }^{24}$ Espinoza CG, Balis JU, Saba SR, Paciga JE, Shelley SA. Ultrastructural and immunohistochemical studies of bronchioloalveolar carcinoma. Cancer 1984;54:2182-9.

${ }^{25}$ Fraire AE, Greenberg SD. Carcinoma and diffuse interstitial fibrosis of the lung. Cancer 1973;31:1078-86.

${ }^{26}$ Raeburn C, Spencer H. A study of the origin and development of lung cancer. Thorax 1953;8:1-10.

${ }^{27}$ Bale J, Juhasz E, Temes J. Pulmonary infarcts and pulmonary carcinoma. Cancer 1956;9:918-22.

${ }^{28}$ Berkheiser SW. Bronchiolar proliferation and metaplasia associated with thromboembolism: a pathological and experimental study. Cancer 1963;16:205-11.

${ }^{29}$ Meyer EC, Liebow AA. Relationship of interstitial pneumonia, honeycombing and atypical epithelial proliferation to cancer of the lung. Cancer 1965;18:322-51.

Request for reprints to: Dr CW Edwards, Department of Histopathology, East Birmingham Hospital, Bordesley Green East, Birmingham B9 5ST, England. 